\title{
Reflections on the Influence of Sharing economy on the University Library Service Development
}

\author{
Gemin Li, \\ Jilin Agricultural University Library, Changchun 130118, China
}

\begin{abstract}
Keywords: Sharing economy; University library; Service development
\end{abstract}
\begin{abstract}
Sharing economy is a brand new economic model derived from practice. With the rapid development of the Internet, the sharing economy has been widely used in many industries, and its influence is increasing in the social economy. This paper analyzes the characteristics of sharing economy as well as the difficulties faced in the university library service development, and discusses some relevant considerations on influence of sharing economy on the university library service development.
\end{abstract}

\section{Introduction}

The core of sharing economy is the fundamental role of information technology, namely, to separate product ownership from usage right and realize the usage right sharing between the product owners and users. University library is an important part of the public service system. It has abundant collection resources, service personnel, professional equipments, related technology and operating venues. But in today's information-based society under Internet age, the survival and development of university library are threatened to some extent and the new model in which various resources are shared also had impact on the library

\section{Characteristics of Sharing Economy and University Library Service Development}

With respective analysis of the characteristics of sharing economy and university library service development, the following section found out the relationship between sharing economy and university library service development and influence of sharing economy on university library service development from such features.

Sharing Economy. Changes in Consumer Attitudes. With the increasing life pressure and the accelerating life pace, people have changed their material attitudes and consumption habits, and increasingly tend to use simple, fast and efficient way of consumption. Under traditional consumption patterns, the consumption is often a transaction of ownership, that is, the customer acquired the exclusive usage right and ownership after the purchase. But in today's consumption environment, this kind of consumption is gradually unsuitable for people's life pace, for the utilization of many products becomes lower and the products are on the shelf most of the time after the purchase, which is a waste of money for the purchaser, but also a waste of social resources. Therefore, people are no longer attached to the consumption pattern with exclusive usage right, but intends to temporarily obtain the ownership when needed, with usage right purchase by many customers and sharing use as the main method.

Promotion of Environmental Awareness. Production and environmental protection contradicts each other. In the traditional consumer environment, people favor exclusive usage right, which led to a significant increase in product demand. Product production is mutually associated with resources, energy and material consumption, so the production increase lead to the destruction of the natural environment. And now people have increasing materials for life and they are more and more desired for the quality of living environment, while reducing the consumption of resources and improving product recycling is the best way to protect the environment. Therefore, the economic development model of sharing economy meets the needs of ecological and environmental protection better than other models. 
Development of Information Technology. In the current information age, information technology is increasingly applied in many fields. The basis for sharing economy development is the scale, with low cost, convenience, selectivity, adaptability and other advantages. However, the reason why this approach is based on the scale is that it needs many people to operate, just like "car sharing", that is, many people cooperate and share the same resources to reduce costs and reach the destination as well. This is the advantage of sharing economy, which improves resource utilization with the same resource expenditure. This scientific trend is more suitable for economic development. In the current era with increasingly developed information technology, the realization of sharing economy is more convenient. The use of "Internet +" and other information technology can provide important technical support for the rapid development of sharing economy.

\section{Development of University Library Service.}

Library Lending Service. Due to the nature of university library as university resources and the influence of space, many university libraries have very limited library resources, and many collected academic books are very close to learning materials in the contents, which is not much helpful for the knowledge expansion of students. In the background of university library service under new era, although there are certain resources sharing and resource exchange between some university libraries, the scope and degree are greatly restricted, only some specific university libraries carry out this kind of resource sharing, and most of the university libraries in China just provide library lending service within the university itself. In today's social development trend under information age, the information resources are updated in an increasing speed. Although the universities invest a lot in the library collection updates, they can hardly keep up with the pace of the times, resulting in more and more narrow knowledge width of the students, so the utilization rate of library as access to knowledge is also being slowly reduced.

Information technology support. Many university libraries have their own resource databases, including Chinese and foreign electronic journals, e-books, masters' and doctoral theses, videos, etc. Such materials cost several hundred thousand yuan each year, even several million yuan each day for some universities, which account for much in the university teaching resources, but different universities have different utilization rates for university library electronic resources, with very low rate in some universities. However, in order to integrate teaching resources with the times, they have to buy the resource databases, so there has been a large amount of waste of resources.

Launching of social services. Although the university library is an important part of the public service system, due to the influence of collection resources, staff and venue, currently there are certain restrictions for university libraries in the service content, service mode, service quantity and service forms. The most universities' use of library is still limited between the teachers and students, and they do not provide services for the public most of time, or even not open to the public. This is greatly different from the university libraries in western developed countries. The limitations of service scope are inconsistent with the universities' functions of serving society, and they are also a great waste of resources.

\section{Relationship between Sharing Economy and University Library Service Development}

The university library service development is mainly embodied in such aspects as "high resource cost", "low resource utilization rate" and "small service scope". According to the above analysis of characteristics of sharing economy, the problems needed to be solved for shared economy conform to those existing in the development of university libraries. The development pattern of sharing economy can bring important development opportunities for the service and innovation of university libraries, and it can also plays an important role in driving the service model expansion of university libraries and the service improvement. Without the support of advanced elements such as "Internet +" and "sharing economy", the service capacity of university libraries will stagnate, or even encounter marginalization.

Establishment of Book Resource Sharing Platform under Sharing Economy. At present, the universities actively carry out digitalization, networking and intelligentization, and in the process of building "Internet + Library" platform, introduce the advanced ideas in sharing economy as guidance, 
conduct service development and transformation in universities libraries in a broader horizon and larger scope, combine physical libraries and network libraries and realize mutual complementation between them, in order to form a service platform with shared ownership, shared management and shared use of book resources.

Shared Ownership Of Book Resources. The platform for shared book resources can take the regionalization pattern and follow the principle of proximity, to realize university library resource sharing. Specifically, it refers to that all the university library resources, public library resources and the books provided by university teachers, students and social readers in a certain region are listed in a book, with the ownership still possessed by certain libraries or individuals, but the usage right owned by all libraries and readers. In addition, the funding proportion by certain libraries, role positioning and resource contribution are the elements to determine the responsibility, power and interests of the libraries and individuals.

Shared Management Of Book Resources. With the help of modern information technology, such as intelligent retrieval, digital resource integration, virtual reality, database, web browsing, mobile Internet, authentication, online payment, etc., taking management personnel and management equipments of university libraries as the basis, it is feasible to conduct unified management for all shared resources, including borrowing reservation, network query, authority management, contribution evaluation, arranged return, inter-library delivery, incentive mechanism, punitive measures, credit management and so on, so as to realize shared management of libraries in a certain region and then inter-region shared management.

Shared Use Of Book Resources. The shared use of library resources includes four aspects, namely, university library, social public library, college teachers and students, and social readers. The book resources from these four aspects have a lot of complementary space in the book content, and application of sharing in these resources is a way to reach multiple purposes. For the university libraries and public libraries, without increasing the venue and acquisition costs, the sharing pattern can significantly increase the total quantity of book resources, and its service staff is no longer confined to the staff of the library. From the aspect of college teachers and students as well as social readers, sharing the use of existing data and library books, cannot only reduce the cost of books purchase, but also have a larger scope in choosing needed books.

Knowledge and Information Flow under the Sharing Economy. It is the main aspect of the university library service under the sharing economy to accelerate the flow of various library resources between universities, social public libraries, college teachers and students as well as the social readers, and improve the utilization rate of book resources to the maximum. On this basis, it is also necessary to deepen the service function, gradually evolve into a wide, broad, three-dimensional and efficient flow of knowledge and information, and take combined sharing of tangible and intangible knowledge with books as the carrier.

Tangible Knowledge Flow of Book Resources. Take the library as the center and transfer station for management of book resources, such as editing, collection, repair, monitoring, etc., introduce book return automatic reminders, off-site return and other convenient means, conduct borrowing and return by ways of regional express and other ways, in order to make the dissemination and flow of books become more efficient and convenient and the resource delivery between four aspects of university libraries, social libraries, college teachers and students and social readers. In the process of sharing books and resources, a lot of library resources are kept by social readers and college teachers and students, so this pattern can reduce the collection pressure of the libraries.

Promotion by intangible information in the library service development. For the library service development, it is needed to make corresponding decisions according to the service objects. For the university libraries under sharing economy, in the process of resource flow, they can collect and analyze the borrowing data and service feedback, and master the readers' behavior characteristics and preferences according to these data, in order to determine the different needs of each reader, and introduce corresponding books to them. In this way, it is feasible to make information feedback to the readers with the help of current new media form, to develop a brand new platform for information dissemination, sharing, delivery and evaluation. 


\section{Construction of Learning Space and Information Space under the Sharing} Economy.University library is the information storage space for universities, but more importantly, it is the open platform for the learning and exchange between college teachers and students. In the future development, university libraries will gradually become a space for information sharing and learning exchange, and they will function as the service platform and learning environment for teachers and students to enhance the ability of independent study and realize the goal of lifelong learning. On the basis of such platforms and environment, the learning and information sharing space for the whole school will transform into such a space for all citizens.

Construction of Learning and Exchange Space. After all, the core role of university libraries is the sharing of learning resources as well as learning and exchange between college teachers, students and social readers. The combination of university libraries and social public libraries is the prerequisite to achieve learning resources sharing by all citizens, specifically, the combination of professional university library collection resources, teaching resources and a wealth of social resources and the establishment of "university open classes" and "community open class" with the characteristics of specialties. Such pattern includes lectures by teachers and combination of online and offline classes. In addition, it is also necessary to introduce various learning resources in the neighborhood near the library and form a space for learning and exchange of all citizens. Moreover, the readers can also organize study groups and research groups to make interactive learning in the space.

Construction of Information Sharing Space. In the future development process, university libraries and social libraries will take digitalization, networking and intelligentization construction, and meanwhile they should cooperate closely and coordinate to reach agreement, to form a space for information exchange and sharing with certain scale and coverage of all learning-related information to provide one-stop systematic service around the clock for readers. It includes lectures, online Q \& A, course information and book order, learning experiences and methods, learning supplies trading and replacement, etc., so that the readers can make knowledge and information sharing anytime and anywhere.

\section{Conclusion}

Sharing economy highly conforms to the needs to solve the difficulties in university library service development. Taking the opportunity of current "Internet + Library" in China university libraries should take action in its field and actively explore the innovative development model of "Sharing economy + Library Service", strive to build a large space for shared ownership, shared management and shared use of book resources, realize big low of knowledge and information with books as the carrier and construct a big space for learning, exchange and information sharing of all citizens, in order to realize multiple resource sharing between university libraries, social public libraries, college teachers and students and social readers, promote the establishment of leaning society and make the libraries exercise greater social value.

\section{References}

[1] Gao Feng. Discussion on the Construction of the Shared Space of University Library under the Background of Reading Promotion - Taking the Library of Hubei University of Economics as an Example [J]. Journal of Library and Information Sciences in Agriculture, 2015,27 (5): 103-105.

[2] Zheng Xiaohong, wang Ming, ma Xiang-yu, et al. Development and Utilization of Information and Learning Shared Space in University Libraries [J]. Sci-Tech Information Development \& Economy, 2014, (14): 38-39, 40.

[3] Chen Yu. The Way of Local University Library to Build a Digital Resource Sharing Platform To Serve The Local Development [J]. Sci-Tech Information Development \& Economy, 2014,24 (8): 110-111,152. 
[4] Xu Xiuxiu, Yang Yinhua, liu Zhihui, et al. Study on the Development of Discipline Services in University Libraries - Based on Analysis of Papers Published in Library and Information Archives Periodicals [J]. Sci-Tech Information Development \& Economy, 2014, (18): 134-136, 142. 